
\& Dossier:

filosofía y literatura 

Acta Poetica 30-2

OTOÑO

2009

\title{
Marx ante (y antes) de la literatura
}

\author{
Eduardo Cadava
}

Este ensayo trata la relación de Marx con la literatura. Busca tomar en cuenta a varios Marxs: 1) el Marx que está obsesionado con la literatura tal como la entendemos generalmente, que evoca en todas partes la literatura de la antigüedad clásica, la literatura de la Edad Media hasta la de Goethe y los escritos de Dante, Cervantes, Shakespeare, Defoe, Balzac, por mencionar sólo algunos de sus favoritos; 2) el Marx que empleó de manera tan frecuente la literatura para analizar la vida histórico-política —que empleó a Balzac para analizar y condenar las políticas reales, que empleó como móviles el Timón de Atenas de Shakespeare o el Robinson Crusoe de Defoe para hablar de procesos económicos que de otro modo hubiesen permanecido oscuros, y que empleó el Don Quijote de Cervantes para criticar a los jóvenes hegelianos_-; 3) el Marx que, a pesar de su propio requerimiento de la literatura, nos cuenta aun que la literatura como tal no existe, ya que está inscrita al interior de un sistema inequitativamente determinado de prácticas socio-históricas y políticas, y relaciones de producción —el Marx, en otras palabras, cuyos análisis materialistas renuncian a la noción del trabajo literario (es decir, a la de un trabajo que sería únicamente literario), incluso al ayudarnos a comprender de qué manera surge, histórica, política e ideológicamente, algo como una institución de literatura-; y 4) el Marx que se lamenta de la literatura, incluso al escribirla — quien quizás regresa a la literatura sobre todo cuando nos dice que no puede existir por sí misma, cuando demuestra que es un elemento esencial de cada modo de representación, cada medio técnico y cada técnica del lenguaje- - Por esto me dispongo a argumentar que el interés de Marx en la literatura es quizás más legible no tanto cuando está hablando de lo que llamamos novelas, poesía, ficción y fábulas, sino cuando se refiere a las ilusiones, alucinaciones, fantasmas, virtualidades y simulacros que componen hoy, más que nunca, nuestra existencia cotidiana. 
Podríamos incluso decir que lo que hace literatura a la literatura es al mismo tiempo lo que le impide permanecer simplemente como literatura, aquello que la hace histórica y política.

Palabras Clave: Marx, literatura y revolución, Blanchot.

This essay deals with Marx's relation to literature. It seeks to give account of several Marxs: 1) the Marx who is obsessed with literature as we generally understand it, who everywhere evokes the literature of classical antiquity, the literature from the middle ages to the age of Goethe and the writings of Dante, Cervantes, Shakespeare, Defoe, Balzac, to name only a few of his favorite references; 2) the Marx who so often used literature to analyze historical-political life - who used Balzac to analyze and condemn royalist politics, who mobilized Shakespeare's Timon of Athens or Defoe's Robinson Crusoe to speak of economic processes that otherwise would remain obscure, and who used Cervantes' Don Quixote to criticize the young Hegelians; 3) the Marx who, despite his recourse to literature, nevertheless tells us that literature as such does not exist, since it is inscribed within an unevenly determined system of socio-historical and political practices and relations of production - the Marx, in other words, whose materialist analyses renounce to the notion of literary work (of a work, that is, that would be solely literary), even as he helps us understand how something like an institution of literature emerges, historically, politically, and ideologically; and 4) the Marx who mourns literature, even as he writes it - who perhaps returns to literature most when he tells us it can never exist by itself, when he demonstrates that it is an essential element of every mode of representation, every technical media, and every technique of language. This is why I will argue that Marx's interest in literature is perhaps most legible when he no longer speaks of what we call novels, poetry, fiction, and fables, but rather when he instead refers to the illusions, hallucinations, phantoms, virtualities, and simulacra that increasingly compose our everyday existence. We could even say that what makes literature literature is at the same time what prevents it from remaining simply literature, what makes it historical and political.

KEY WORDS: Marx, revolution and literature, Blanchot.

Fecha de recepción: 13 de febrero de 2010

Fecha de aceptación: 4 de julio de 2010 
Eduardo Cadava

Universidad de Princeton

\section{Marx ante (y antes) de la literatura}

Traducción de Mariela Pacchioli

El lenguaje es el medio de la futuridad [...]

El lenguaje es un medio en la medida en que abre

el lugar de llegada, abre la puerta a lo que vendrá.

Werner HAMACHeR

Para empezar, podríamos preguntarnos porqué Marx recurre tan a menudo, una y otra vez, no sólo al lenguaje literario sino también a la literatura, no sólo a las transformaciones históricas y políticas sino también al lenguaje sin el cual estos cambios nunca sucederían. Si regreso a Marx en este ensayo, lo hago en reconocimiento de la inevitabilidad de su pensamiento - tanto para mí como para nuestra época- pero también porque, al tratar de especificar sus instrumentos de análisis, intento señalar, y quizás liberar, los recursos que Marx mismo movilizó en su esfuerzo por hacer realidad la promesa de una democracia y un comunismo que, por primera vez, inaugurarían una nueva historia universal de liberación, justicia e igualdad. Muchos de esos recursos se encuentran en lo que Marx llama "literatura". Si me dirijo ahora a un nuevo conjunto de referencias, es porque, como Marx mismo sugirió tantas veces, quizás estamos 
más cerca de lo que deseamos analizar en el momento mismo en que parecemos estar más lejos. He de comenzar nuevamente, entonces, pero esta vez con el Marx que, incluso al afirmar que renunciaba a la literatura, de todos modos seguía escribiéndola, sin alejarse de ella, pidiéndonos que le prestáramos atención, como si estuviéramos escuchando una especie de secreto.

En una carta escrita a su padre el 10 de noviembre de 1837, Marx sugiere que ha llegado a un punto crucial en su vida - un momento que marca una especie de frontera, un momento de transición y transformación, tal vez hasta un momento revolucionario-_. "En semejantes momentos", escribe:

el individuo se vuelve lírico, pues toda metamorfosis es, en parte, canto de cisne y, en parte, obertura de una gran poesía... Querríamos levantar un monumento a lo que ya hemos vivido, como si debiera recuperar en el sentimiento el lugar que ha perdido para la acción (Marx, "Carta al padre", 17-18).

Como descubrimos leyendo el resto de la carta, a lo que Marx supuestamente ha sobrevivido, aquello que ha superado, es su deseo de escribir literatura. Su carta busca dar cuenta a su padre de su decisión de abandonar la literatura para continuar sus estudios en leyes, filosofía, historia y economía. Ofrece a su padre la historia de su decisión, dándole en orden cronológico una lista de varios de los libros que ha leído desde el principio de sus estudios en Berlín. Admite que, cuando recién ingresó a la escuela, se sentía atraído hacia la poesía lírica. Buscaba "las danzas de las musas y la música de los sátiros" (25), le dice a su padre, $y$, en su escritura, deseaba encontrar un lenguaje que le permitiera realizar lo que él llama un "fuego poético" (27).

Describe sus tempranos esfuerzos literarios - una novela incompleta, comenzada en 1835 titulada Escorpión y Félix; 
un libro de poemas escrito en 1836, titulado El libro de amor, dedicado a Jenny, su esposa; una colección de poemas titulada Canciones Salvajes, escrita en 1837 y dedicada a su padre; y su tragedia incompleta, Oulanem - aunque agrega que, de a poco, el espectro y la exigencia de sus estudios lo llevaron a ver estos escritos como un acompañamiento de sus otros estudios-. Las contradictorias demandas de sus clases, en otras palabras - quizás una versión temprana de lo que más tarde entendería como conflicto de clase-, lo llevaron a repensar su relación con la literatura. Al reconstruir este cambio en su forma de pensar en relación a los libros que estaba leyendo - textos de Aristóteles, Tácito, Ovidio, Kant, Schelling, Fichte, Lessing, Winckelmann, Feuerbach, entre otros-, recuerda que los síntomas de su conflicto creciente incluían no sólo un alejamiento del mundo sino también - y esto en respuesta a su renuncia a la literatura - una enfermedad prolongada que eventualmente fue curada sólo al leer nuevamente a Hegel. Tan pronto como se recuperó, inmediatamente quemó sus poemas y relatos, imaginándose, como él mismo dice, que de esa manera podía renunciar a ellos completamente.

A lo largo de la carta, este alejamiento de la literatura se ve reforzado por la creciente sospecha de que sus aspiraciones como escritor se frustrarán. Como le dice a su padre, en relación a Oulanem,

estas últimas poesías son las únicas en las que súbitamente, como mediante un golpe mágico - ¡ay! El golpe fue al comienzo demoledor-, se encendió el reino de la verdadera poesía, como un lejano palacio de hadas, y todas mis creaciones se convirtieron en nada (25).

En todo caso, si estas líneas sugieren que sus creaciones literarias nunca van a ocupar el reino de la poesía - si sus escritos literarios quedan reducidos a polvo frente al esplendor 
de la poesía verdadera, o si, como escribe en otra parte de la carta, en lugar de alcanzar una "forma real", fue sólo capaz de construir un "escritorio con cajoncitos en los que después ech[ó] (él mismo) arena" (21)—, tampoco le impiden su retorno a la poesía, ya que su encuentro mágico con la poesía sólo lo destruyó “al principio". Si leemos esta carta detenidamente, y prestamos atención a sus rasgos marcadamente literarios y retóricos, hasta podríamos decir que el retorno de Marx a la literatura ocurre en la misma carta en la que declara su alejamiento; que es en sí un "canto del cisne" o una despedida de la poesía. Se podría arriesgar no sólo que la carta misma es muy lírica - caracterización que el mismo Marx autoriza ya que, como ya ha dicho, hay un cierto lirismo en todo momento de metamorfosis y transformación - sino que la puesta en escena completa de la carta es "literaria". Con el fin de marcar este momento de transición - de la literatura a la ley, la filosofía, la historia y la economía, de un Marx a otro-, Marx llega a decir que "ha caído un telón" (26).

Cuando se empiezan a apagar y bajar las luces, el teatro en el que Marx persiguió antes sus intereses literarios anuncia aquí una muerte. Un cierto Marx busca deliberadamente llegar a su fin mientras otro Marx lucha por su supervivencia, más allá de esta muerte, como una especie de fantasma. Esta dimensión fantasmal está confirmada por el contexto en el cual Marx le escribe a su padre. En una breve postdata a la carta, Marx se disculpa por la ilegibilidad de su letra - la que atribuye al hecho de que está escribiendo la carta en la oscuridad, que ya son las cuatro de la madrugada y a que su vela se ha extinguido hace tiempo-; le confiesa a su padre que su visión es borrosa, que apenas puede ver algo, que está muy perturbado e inquieto, $y$, finalmente, que se encuentra rodeado de "espectros agitados" (28), espectros que han llegado con la oscuridad invasora pero que, sintomáticamente, también pertenecen a la ansiedad y dificultades ocasionadas por su decisión de abandonar la literatura. 
Escribiendo bajo la disminuida luz de una vela, en medio de las parpadeantes sombras que ocupan su cuarto y sus páginas, Marx experimenta la soledad de una oscuridad repleta de espectros. Al escribir a través de las cambiantes y parpadeantes sombras producidas al derretirse la vela, escribe en un espacio que, siguiendo a Mallarmé, podríamos llamar el medio exacto de la poesía. Estas sombras cambiantes alegorizan la incertidumbre con la que procura abandonar la literatura y señalan, como medios del trabajo literario, la metamorfosis dentro de la cual, como Marx lo presenta, podría escribirse la "obertura de un nuevo y gran poema" (17). Si la carta de Marx busca sugerir que ha decidido alejarse de la literatura, deja sin embargo abierta la posibilidad de que perseguirá la poesía por otros medios. Podríamos incluso decir que este "nuevo y gran poema", este otro tipo de poesía, será escrito y reescrito en todo su trabajo por venir.

Lo que quiero decir con esto $-\mathrm{y}$ es por lo cual he deseado empezar con esta notable carta, una de las primeras cartas que tenemos de Marx - es que Marx nunca fue capaz de dejar atrás la literatura. Y quizás fue incluso menos capaz de dejarla atrás cuando se sintió obligado, una y otra vez, a renunciar a ella. Si Marx necesita recordar la literatura, pero sólo con el fin de olvidarla, es para que, como Blanchot hubiera dicho, "en ese olvido, en el silencio de una profunda metamorfosis, nazca al fin una palabra, la primera palabra de un verso" (Blanchot, "La obra y el espacio de la muerte", 79). Si la carta de Marx nos llega bajo la forma de un monumento a la literatura, entonces, también anticipa todas las conmemoraciones futuras de la literatura. Tomadas en conjunto, me gustaría argumentar que estas conmemoraciones constituyen la totalidad del corpus de Marx. De hecho, no hay momento en Marx que no haya sido tocado por la literatura, y tal vez este sea especialmente el caso cuando hace su duelo.

En lo que resta de esta presentación, me gustaría analizar esta aparente paradoja "poniendo en movimiento" una serie de 
reflexiones sobre la relación de Marx con la literatura. ¿Qué es la literatura para Marx? ¿Dónde se imaginó él ante ella? ¿Qué pensó de ella cuando estaba ante ella? ¿De qué manera podríamos decir que Marx estuvo siempre ante la literatura? Empiezo entonces nuevamente, y esta vez, con Marx ante (y antes de) la literatura.

Marx ante la literatura. Esto significa Marx ante o frente a la literatura, Marx encontrándose o involucrándose con la literatura: mirándola, analizándola, hasta tocándola, pero también, quizás, manteniendo una distancia respecto de ella, cuestionándola desde una proximidad y una distancia que, a su vez, hace de su relación con la literatura algo que debe ser leído - y tal vez no sólo en Marx.

Marx ante la literatura. Esto significa Marx encontrándose con la literatura de la antigüedad clásica, la literatura alemana desde la Edad Media hasta los tiempos de Goethe, los mundos de Dante, Tasso, Cervantes y Shakespeare, la ficción francesa e inglesa de los siglos dieciocho y diecinueve. Esto se refiere al Marx del que se decía que conocía a Heine y Goethe de memoria, que leía a Esquilo en griego todos los años. El que consideraba a Shakespeare como el mayor genio del drama que jamás hubiera existido, el que admiraba tanto a Balzac que deseaba escribir una reseña de su Comedia Humana apenas hubiera terminado su libro sobre economía. El Marx que leyó a sus hijas la obra de Homero, el Don Quijote, y Las mil y una noches enteros, y el que las alentó a memorizar y recitar escenas enteras de las obras de Shakespeare. ${ }^{1}$ Esto se refiere al Marx para quien los textos literarios se convirtieron en acontecimientos dentro de sus textos, y cuya práctica de cita y alusión no sólo conso-

${ }^{1}$ Para una introducción interesante a la lectura de la literatura de Marx -incluyendo una suerte de lista de lectura de los escritores en quienes Marx estaba más interesado_- cfr. S. S. Prawer, Karl Marx and World Literature. 
lida la relación que él vislumbra entre el pasado y el presente, entre un acontecimiento y su representación, sino también su sospecha de que la literatura tiene la capacidad de inventar un futuro que no sería simplemente una repetición del pasado.

Marx ante y antes de la literatura. Esto también supone que no puede haber literatura antes de Marx, que la literatura sólo puede ser comprendida, si es que la literatura puede ser comprendida de alguna manera, a través de Marx, a través de lo que hemos heredado de sus textos y legados - lo hayamos leído o no-, pues el nombre propio "Marx" siempre ha sido sinónimo de análisis de la literatura - ya sea por sus constantes referencias, entre tantos otros, a Shakespeare, Cervantes, Goethe, Heine, Hugo y Balzac, o como sucede con frecuencia, por los trabajos que retoman su nombre y sus textos, como Literatura y Revolución de Trotstky, los escritos de Lenin sobre Tolstoi, los ensayos literarios de Adorno, las reflexiones de Bajtín sobre Dostoievski, los escritos de Benjamin sobre Baudelaire, las lecturas del realismo y el naturalismo de Lukács, los ensayos de Sartre sobre Flaubert, y los textos de Jameson sobre Balzac y Conrad-. Que no pueda haber literatura antes de Marx, no obstante, también significa que, con Marx, frente a Marx, la literatura como tal no existe. Inscrita dentro de un parcialmente determinado sistema de prácticas socio-políticas, pertenece a una red entera de relaciones sociales de producción que están históricamente determinadas y relacionadas a otras formas ideológicas. Esto quiere decir que el análisis materialista de la literatura renuncia a la idea de obra literaria - a la apariencia ilusoria de la unidad de un texto, su autosuficiencia y perfección - porque, como diría Marx, la literatura nunca es simplemente "literatura". Esta es la razón por la cual "no puede haber literatura antes de Marx", lo cual también significa que es sólo con Marx, frente a Marx, que podemos empezar a entender cómo algo como la institución literaria emerge históricamente, políticamente e ideológicamente. Como diría Jameson, las perspectivas del marxismo 
no son sólo precondiciones necesarias para entender la literatura: son también las precondiciones semánticas primordiales para la inteligibilidad de los textos literarios y culturales en general. ${ }^{2}$

Marx antes de la literatura. Esto sugiere que Marx siempre estuvo ante la literatura, frente a la literatura, siempre estuvo interesado en analizarla y en usarla para analizar la vida histórica y política. Esto se refiere al Marx que usaba a Balzac para analizar y denunciar las políticas monárquicas, al Marx que utilizaba el Timón de Atenas de Shakespeare o el Robinson Crusoe de Defoe para hablar de procesos económicos que, para él, resultaban oscuros en la vida real; el Marx que usaba Los misterios de París de Eugenio Sue para hablar de las limitaciones que el condicionamiento de clase pone a la ficción social. Esto también se refiere al Marx que, en La ideología alemana, usó el Quijote de Cervantes con el fin de apropiarse, resituar y luego liberar su potencial crítico para criticar a los jóvenes hegelianos, Ludwig Feuerbach, Bruno Bauer y Max Stirner.

Aunque críticos desde Lukács hasta Jameson han sugerido frecuentemente que las historias marxistas de la literatura moderna empezarían con Don Quijote y los comienzos del realismo novelesco, con excepción de cinco páginas del ensayo de Robert Kaufman, "Red Kant", nadie ha estudiado y analizado el papel de la novela de Cervantes en La ideología alemana (y en gran medida porque, cuando leemos el texto, la mayoría de las veces nos limitamos a la sección sobre Feuerbach). ${ }^{3}$ Dado que no se ha prestado atención a esto, me gustaría detenerme por un momento para ofrecer una breve idea de la manera extraordinaria en que Marx y Engels ejecutan, mediante el movimiento de su escritura, lo que desean que entendamos.

${ }^{2}$ Si bien Jameson explica su punto de vista en varios textos, quizás su versión más elaborada se encuentra en su libro The Political Unconscious: Narrative as a Socially Symbolic Act.

${ }^{3}$ Cfr. Robert Kaufman, "Red Kant, or the Persistence of the Third 'Critique' in Adorno and Jameson". 
En La ideología alemana buscan desafiar la retórica y las afirmaciones de la filosofía política de la izquierda alemana, y lo hacen inhabilitando y desplazando esta misma retórica. El texto empieza con la sugerencia, por parte de Marx y Engels en el contexto de los debates internos de la izquierda alemana, de que los jóvenes hegelianos se han esforzado por separar los movimientos revolucionarios de "la concepción materialista de la historia", minimizando la importancia del modo de producción en nombre de una conciencia crítica que, según ellos, concibe las ideas como el motor principal de la historia. A causa de esto, argumentan Marx y Engels, estos idealistas hegelianos - refiriéndose en particular a Feuerbach, Bauer y Stirner- revelan su conservadurismo político y filosófico, a pesar de sus frases supuestamente subversivas. "La filosofía hegeliana de la historia es la última consecuencia [...] de toda esta historiografía alemana", escriben,

que no gira en torno a los intereses reales, ni siquiera a los intereses políticos, sino en torno a pensamientos puros, que más tarde San Bruno se representará necesariamente como una serie de "pensamientos" que se devoran los unos a otros, hasta que, por último, en este entredevorarse, perece la "autoconciencia", y por este mismo camino marcha de un modo todavía más consecuente San Max Stirner, quien, volviéndose totalmente de espaldas a la historia real, tiene que presentar todo el proceso histórico como una simple historia de "caballeros", bandidos y espectros (Marx y Engels, La ideología alemana, 42).

Marx y Engels amplían su crítica en la segunda sección de La ideología alemana, titulada "El Consejo de Leipzig", debido al hecho de que los recientes libros de Bauer y Stirner habían sido publicados en Leipzig. La sección entera intenta reforzar la tesis de Marx y Engels de que estos dos escritores son indiferentes —en detrimento de su pensamiento y posición política - a los procesos de la vida material. La sección se abre 
con una evocación de la famosa pintura "La Batalla de los Hunos" de Wilhem von Kaulbach. Basada en la batalla librada entre los hunos y los romanos en Châlons en el año 451, Kaulbach representa los fantasmas de los guerreros caídos peleando en el aire sobre el campo de batalla. Tomando como punto de partida este cuadro, Marx escribe:

los espíritus de los abatidos, cuya cólera no ha apaciguado ni siquiera la muerte, atruenan el espacio con su estrépito, sus bramidos, como un clamor de guerra y un ruido ensordecedor de espadas, escudos y carros de combate. Pero no se trata de cosas terrenales. En esta guerra Santa no se ventilan los aranceles protectores, la Constitución, la enfermedad de las patatas, el régimen bancario o los ferrocarriles, sino los más sagrados intereses del espíritu, la "sustancia", la "autoconciencia", la "crítica", el "Único", y el "hombre verdadero". Estamos ante un Concilio de Padres de la Iglesia (91).

Marx luego continúa presentándonos a los miembros del Concilio. "Tenemos, en primer lugar, a San Bruno", escribe, "ciñe su cabeza la gloriola de la 'Crítica pura' y se envuelve, con gesto que desprecia al mundo, en su 'autoconciencia'. [Es] el 'Napoleón' del espíritu, y en espíritu 'Napoleón' [...] Frente a él aparece San Max [...] es a un tiempo [...] Sancho Panza y Don Quijote" (91-92).

Como indica este pasaje, Marx y Engels presentan y hacen uso de una serie de sobrenombres, metáforas y alegorías irónicas y sarcásticas para referirse a Bauer y Stirner, y lo hacen en relación a dos conceptos literarios y críticos, los cuales ayudan a enmarcar su crítica. La primera figura, "El Concilio de Leipzig”, es, en palabras de Kaufman, "un espectáculo burlesco del Antiguo y del Nuevo Testamento, con los jóvenes hegelianos (llamados 'San Bruno' y 'San Max') llevados a juicio en la parodia de la Inquisición de Marx y Engels" ("Red Kant”, 697). La segunda, reforzando la primera, supone el uso continuo, ex- 
tendido y crítico del Quijote. Al citar largos pasajes de Bauer y Stirner en su crítica de los dos hegelianos, Marx y Engels inscriben a estas dos figuras en su propio Quijote, asociándolas alternativamente con Sancho Panza y Don Quijote, y a veces con los dos simultáneamente. Para no extenderme, simplemente voy a citar tres ejemplos de la manera en que esta forma de reescritura funciona.

Primero, el pasaje en el que Marx y Engels acusan a San Max de producir una historiografía de ideas ilusorias, una historia de espíritus y fantasmas. Escriben:

Ahora bien, como San Max comparte con todos los especuladores críticos de los tiempos modernos la creencia de que los pensamientos objetivados, corporeizados - los fantasmashan dominado y dominan el mundo, de que toda la historia hasta ahora, ha sido la historia de la teología, nada más fácil que convertir esta historia en una historia de fantasmas. La historia de los fantasmas de Sancho descansa, por tanto, sobre la creencia tradicional de los que especulan sobre los fantasmas ( $\mathrm{La}$ ideología alemana, 160).

Segundo, un pasaje más largo que entreteje más explícitamente los textos de Stirner y Bauer con el de Cervantes: "la lucha por el 'hombre"', nos dicen Marx y Engels,

[...] es la realización de aquellas palabras, escritas por Cervantes, en el capítulo XXI de su obra, "que trata de la aventura y rica ganancia del yelmo de Mambrino". Nuestro Sancho que todo le imita a su antiguo amo y actual escudero, ha "jurado conquistar el yelmo de Mambrino" [es decir] a los hombres para sí. Y después de buscar en vano el ansiado yelmo, durante sus distintas "salidas" entre los antiguos y modernos [es decir] los liberales y los comunistas [Sancho-Max] "descubrió a un hombre a caballo que traía en la cabeza una cosa que relumbraba como si fuera de oro" [...] Entre tanto, se acerca el santo barbero Bruno, cabalgando apaciblemente su borrica, la crítica, 
con su bacía de barro sobre la cabeza; San Sancho endereza contra él su lanza, San Bruno salta de la burra al suelo, deja atrás la bacía [...] y corre a campo traviesa, "porque es el crítico en persona" (238-39).

Y tercero, un pasaje en el que Marx y Engels sugieren que el argumento de Stirner funciona a menudo a través de una serie de aposiciones que no guardan una relación clara entre sí:

Ante estas trabajosas preguntas y questinculis, se comprende muy bien la indiferencia de nuestro Sancho para quien todo es uno y lo mismo y que da de lado a todas las distinciones, reales, prácticas y discursivas. En general, podemos decir, ya desde ahora, su arte para confundir, para hacer que todos los gatos sean pardos en la noche de lo sagrado, y para reducir lo todo a todo, arte que encuentra su expresión adecuada en el método de la aposición [...] La aposición es el rucio de San Sancho, su locomotora lógica e histórica, la fuerza propulsora "del Libro", reducido a su más breve y más simple expresión (274).

Cuando registramos lo que Marx y Engels logran aquí con su Quijote salvaje, podríamos preguntarnos, junto con Kaufman, si el Pierre Menard de Borges "encuentra secretamente su ascendencia en este notable texto de materialismo histórico" (Kaufman, "Red Kant", 699). Al convertir el Quijote de Cervantes en una parte esencial de su análisis de la ideología y de la teoría del modo de producción, Marx y Engels presentan una teoría de la novela, pero una en la cual parece no haber una clara distinción entre ficción y filosofía, entre ficción y análisis político. La fidelidad del personaje de Don Quijote (y esto significa también la de Bauer y Stirner) a una filosofía política abstracta e idealista lo condena a él, y en consecuencia a ellos, a vivir una ficción, y por último, a no entender ni la historia ni la ficción. Pero aquí, el realismo literario cervantino transforma la ficción en "un medio para delinear, si bien aporéticamente, la complicada negociación moderna con la realidad histórica y material." Como bien 
sabía Marx, Don Quijote es una de las grandes meditaciones sobre las relaciones entre ficción y realidad, ideas y materialidad, ideología y modos de producción. No es por accidente, entonces, que aquí Marx acuda a Cervantes, ya que, como Marx y Engels, Cervantes también procede en su novela a través de una serie de discusiones literarias, comentarios críticos y debates filológicos que, a pesar de su aparente condición de azarosos, converge en una serie de reflexiones sobre el sentido, la interpretación y la materialidad de las palabras.

En los análisis presentados en conjunto por Marx y Engels, los desplazamientos, malentendidos e interrupciones de sentido que ocurren entre Sancho y el Quijote se vuelven una lente a través de la cual se pueden leer los desplazamientos y malentendidos que caracterizan la escritura filosófico-política de Bauer y Stirner. El juego de nombres y sobrenombres que Marx y Engels hacen circular dentro de su argumento paródico y sarcástico tiene también sus precursores en la pluralidad de máscaras, nombres y pseudónimos detrás de los que usualmente Cervantes se presenta; y la novela en sí misma evoca el mundo moderno que estos dos comunistas han heredado y que intentan analizar en oposición a Bauer y Stirner: un mundo que exhibe las marcas del imperialismo y colonialismo, inmigración y migración, pobreza y distribución desigual de riquezas y poder, muerte y despoblación, y las vicisitudes de la transición de las economías feudales al capitalismo; un mundo que contrastó sus mitos con sus realidades, un mundo que se aisló de sus realidades, prefiriendo soñar. ${ }^{4} \mathrm{El}$ hecho de que Don Quijote retenga hasta hoy su valor político queda confirmado por el subcomandante Mar-

${ }^{4}$ Aunque la literatura crítica de la novela de Cervantes es vasta, he encontrado que en Cervantes in Algiers: A Captive's Tale, de María Antonia Garces y Unspeakable Subjects: The Genealogy of the Event in Early Modern Europe, de Jacques Lezra, resuenan algunos de los problemas que aquí me preocupan. 
cos, quien, en una entrevista con Gabriel García Márquez del 2001, señala que "El Quijote es el mejor libro de teoría política que hay en circulación, seguido de Hamlet y Macbeth" (subcomandante Marcos, "The Punch Card and the Hourglass").

El uso que Marx hace de Don Quijote sugiere que su interés en la literatura es tal vez aún más legible cuando deja de hablar sólo de lo que llamamos novelas, poesía y fábulas, que cuando, por el contrario, habla de las ilusiones, alucinaciones, fantasmas y simulacros que componen lo que todavía hoy, más que nunca, llamamos nuestra existencia cotidiana. Marx toca el reino de la literatura, ese mundo fantasmagórico e imaginario que asociamos, justa o injustamente, con la marca de lo literario. Ya esté describiendo y analizando el teatro de la Europa moderna, cuyos proyectos de unificación dan voz al sentido y a los efectos del capital; ya esté hablando sobre el carácter aparente del dinero o de la ideología, o se refiera al carácter espectral de la mercancía y el valor de cambio - una revolución social que sólo puede extraer su poesía del futuro, la relación ideológica o imaginaria entre los individuos y sus condiciones reales de existencia, la alucinante personificación de su famosa mesa que baila y gira, el reino nebuloso de la religión, la teatralidad de la representación política-; o se refiera a lo que él llama en La ideología alemana los "fantasmas formados en los cerebros de los hombres" (56).

Para decirlo con otras palabras, lo que hace que la literatura sea literatura - su capacidad de comprometer y producir relaciones ilusorias, imaginarias y fantasmales - es al mismo tiempo lo que le impide ser simplemente literatura, lo que la vuelve histórica y política. Cuando, en su famosa carta a Margaret Harknee de 1888, Engels afirma haber aprendido más acerca de la sociedad francesa y su historia a través de Balzac "que a través de todos los supuestos historiadores, economistas y expertos en estadística del período juntos" (Marx y Engels, Cuestiones de arte y literatura,137), está anunciando otra interpretación de la literatura, una que nos pide que hagamos 
duelo por ella para que podamos reconocerla por lo que es: nunca simplemente literatura.

Marx ante la literatura, entonces. Se refiere a un encuentro, un encuentro entre, además de tantas otras cosas, literatura, política, filosofía, historia, religión y economía. En su sentido más amplio, sin embargo, se refiere al encuentro entre Marx y las actividades de escribir y leer. Estas dos actividades - que pertenecen esencialmente a la "literatura", como Marx y nosotros la entendemos, pero que nunca son dos actividades totalmente distintas - no requieren prácticas políticas; ellas son, en todas sus manifestaciones, prácticas políticas. Esta conexión entre lectura, escritura y política, sin embargo, se ha mantenido distante, secreta y casi desconocida para el mismo comunismo - por lo menos después de Marx- excepto en la explosión de poesía, pintura y cine a principios de la revolución soviética, los motivos que Benjamin admite como razones para llamarse marxista, o lo que Blanchot trató de acercar o proponer (más que significar) con la palabra "comunismo". Mientras nos esforzamos por reconocer esto, quizás surjan otras luchas que sean tanto políticas como literarias, luchas que ya no presuman una distancia absoluta entre las lecturas de Marx y los intentos de cambiar el mundo, luchas que pertenezcan a lo que, en una serie de meditaciones sobre los escritos de Blanchot y Bataille, Jean-Luc Nancy ha llamado "comunismo literario", algo que le daría nombre al modo de compartir y a lo que comparte la comunidad dentro de sí misma y a través de su escritura, su literatura. Comienzo nuevamente, pero esta vez con Blanchot en Marx.

\section{$* * *$}

En "Los tres lenguajes de Marx", un breve ensayo escrito tras los disturbios de mayo del '68, Blanchot sugiere que hay en

${ }^{5}$ Nancy, "El comunismo literario", 123-136. 
Marx por lo menos tres voces diferentes pero relacionadas: una que caracteriza a Marx como un "escritor de pensamiento" (94), una "política", y una que evoca el lenguaje indirecto del "discurso científico" (95). "El contraste que [mantiene a estos lenguajes] juntos", escribe, "designa una pluralidad de exigencias a las que desde Marx, cada uno, al hablar, al escribir, no deja de sentirse sometido, salvo que se sienta carente de todo" (94). En el momento en que hablamos o escribimos, en otras palabras, no sólo pensamos, actuamos y articulamos una relación con el conocimiento, sino que también somos llamados a múltiples responsabilidades. Según Blanchot, sin embargo, en cada instancia, estamos expuestos a acontecimientos y experiencias que no pueden calcularse o programarse, y que por lo tanto exigen respuestas que no podemos dar, al menos no sobre la base de algo que podamos saber o controlar. El escritor responsable, por ejemplo, responde al dolor de la "alienación, de la primacía de la necesidad, la historia como el proceso de una práctica material", y la humanidad, la falta de humanidad del hombre, "deja, sin embargo, indeterminadas o imprecisas las preguntas a que [él] responde" (94). En cada instancia, Blanchot sugiere que la posibilidad misma del comunismo, del pensamiento o la acción política, surge con el apartamiento del pensamiento y la acción del dominio del conocimiento. Escribe:

El ejemplo de Marx nos ha ayudado a comprender que el lenguaje de escritura, lenguaje de contestación incesante, debe constantemente desarrollarse y romperse bajo formas múltiples. El lenguaje comunista es siempre a la vez tácito y violento, político y sabio, directo, indirecto, total y fragmentario, lento y casi instantáneo. Marx no vive cómodamente en esta pluralidad de lenguajes que siempre tropiezan y se desunen en él (95).

La inconmensurabilidad de los lenguajes de Marx también está conectada al hecho de que cada uno de estos lenguajes nunca es 
idéntico a sí mismo, lo que significa que no sólo no pueden ser retraducidos los unos a los otros, sino que tampoco pueden ser traducidos a sí mismos. Es esta extrañeza dentro del lenguaje mismo la que, para Blanchot, abre las actividades de traducción, comparación y escritura a la literatura. Sugiriendo que la heterogeneidad compleja de los textos de Marx hace difícil circunscribirlos, Blanchot observa que los gestos de su escritura resisten, desde el comienzo, todos nuestros esfuerzos por ordenar o estabilizar lo que podemos llamar su "pensamiento". Ya que los lenguajes de Marx permanecen inconmensurables unos con otros, Blanchot continúa recordándonos

que ningún escritor, por más que fuera marxista, podría remitirse a la escritura como a un saber, pues la literatura (la exigencia de escribir, cuando toma a su cargo todas las fuerzas y formas de disolución, de transferencia) no se hace ciencia más que por el mismo movimiento que lleva a la ciencia a hacerse a su vez literatura, discurso inscrito, eso que cae como desde siempre en "el insensato juego de escribir" (96).

Es evidente que aquí hay implícita una política del discurso y la escritura pero se trata de una política en la cual la certeza de conocimiento se disuelve para transformarse en literatura. No sería una exageración decir que, para Blanchot, el comunismo es una comunidad de literatura, una relación sin relación que toma su punto de partida en la actividad de escribir. Lo que debe entenderse por esto, sin embargo, no puede equipararse, como Nancy ha demostrado en La comunidad inoperante, ni a la idea de "comunismo" ni a la idea de "literatura" como las entendemos generalmente. En palabras de Nancy,

no determina un modo particular de socialidad, y [...] no funda una política [...] Sino que esto define al menos un límite en el cual toda política comienza y se detiene [...] remite en cambio a lo que resiste a la definición y al programa (Nancy, "El comunismo literario", 136). 
Blanchot confirma este punto en un pasaje extraordinario de su ensayo de 1948, "La literatura y el derecho a la muerte", registrando la ineludible relación entre revolución y literatura, una relación que emerge cuando, como él explica, un escritor "encuentra en la historia esos momentos decisivos en que todo parece en tela de juicio, en que la ley, la fe, el Estado, el mundo de arriba, el mundo de ayer, todo se hunde sin esfuerzo, sin trabajo, en la nada", escribe,

a esas épocas se les llama Revolución. En ese instante, la libertad pretende realizarse en la forma inmediata del todo es posible, todo puede hacerse. Momento fabuloso, del que no puede sobreponerse por entero quien lo haya conocido, pues ha conocido la historia como su propia historia y su propia libertad como libertad universal. Momentos en efecto fabulosos: en ellos habla la fábula, la palabra de la fábula se hace en ellos acción. Nada más justo que tienten al escritor. La acción revolucionaria es por todos conceptos análoga a la acción, tal como la encarna la literatura: paso de la nada al todo, afirmación del absoluto como acontecimiento y de cada acontecimiento como absoluto. La acción revolucionaria se desencadena con la misma fuerza y la misma facilidad que el escritor, quien para cambiar al mundo sólo necesita alinear unas palabras [...] El escritor se reconoce en la Revolución. Lo atrae porque es el tiempo en que la literatura se hace historia [...] Todo escritor, por el propio hecho de escribir, no es llevado a pensar: soy la revolución, sólo la libertad me hace escribir, no escribe en realidad (37-38, 40-41).

No puede haber revolución, indica Blanchot, sin literatura, sin fábulas que se transformen en acción, que hagan historia. Esto no significa que los actos de revolución - los diversos actos de escritura, violencia, asesinato y batalla que anuncian usualmente el acontecimiento de revolución — sean sólo palabras, sino que tienen que ser expresados con palabras: requieren de actos de persuasión, de argumentos, debates, órdenes y reglas que son a la vez la fuerza, la provocación y los efectos de la revolución; 
requieren de actos de lenguaje y representación sin los que ninguna política sería necesaria o posible. Esto es simplemente para decir lo que tal vez siempre supimos: la lucha política se pone en escena sobre la superficie de la representación. Cuando Marx escribe El dieciocho brumario, por ejemplo, insiste, demuestra, que la representación debe ser tomada seriamente porque lo que ejecuta y posibilita es inseparable de lo que el mundo va a ser. Al enfatizar la materialidad y la fuerza de los conceptos ideológicos, indica que lo ocurrido en Francia entre 1848 y 1851 involucró, entre otras cosas, varias prácticas discursivas que, declarando su independencia de los procesos físicos de la vida, integraron lo que decían en los procesos de la vida real. Es por esto que, señala, "mientras se respetase el nombre de la libertad y sólo se impidiese su aplicación real y efectiva - por la vía legal se entiende - la existencia constitucional de la libertad permanecería íntegra, intacta, por mucho que su existencia real fuera reducida a cero". ${ }^{6}$ Escribiendo en cursiva "nombre" y "vida real", Marx busca no sólo enfatizar el contraste de La ideología alemana entre realidad material y lo que es dicho e imaginado — un contraste que también busca complicar (como Cervantes hizo en Don Quijote) - sino también sugerir que las palabras y nombres tienen un papel esencial en lo que llamamos "vida real". Si, en su contexto inmediato, la afirmación de Marx critica irónicamente el lenguaje separado de la realidad, en el contexto más amplio de El dieciocho brumario, tales aseveraciones son un componente fundamental de la realidad vivida por Francia y sus ciudadanos. Basando mucho de su poder en el efecto de su nombre, Napoleón III consolidó su posición haciendo que otras palabras y nombres cambiaran el mundo, a pesar de su incapacidad para describirlo. Es por esto que, explica Marx, si el ascenso de Napoleón fue

${ }^{6}$ Por cuestiones de traducción, únicamente para esta cita de El dieciocho brumario de Luis Bonaparte, preferimos la traducción de O. P. Sanfot. 
resultado de la fuerza de la ilusión, la historia de la humanidad fue alterada por una sombra sin sustancia. En palabras de Sandy Petrey,

el espectro de la revolución se materializa por medio de la resolución apasionada que inspira en la praxis de aquellos a los que aterroriza. Que Marx identifique a los hombres y acontecimientos como sombras sin cuerpo de ningún modo revoca el imperativo marxista a explicar el mundo que producen hombres y acontecimientos. Lo único que cambia es la forma que debe tomar la explicación (Petrey, "The Reality of Representation”, 76).

Como explica Marx, lo que Napoleón III representa no es el campesinado como existe en la práctica material y el proceso social, sino como éste se imagina a sí mismo nostálgicamente en su conciencia. En otras palabras, la ideología de Napoleón III no expresa la realidad concreta de la existencia económica, sino las fantasías salvajes de otra ideología. "Uno ve", escribe Marx, que "todas las idées napoléoniennes son las ideas de la parcela incipiente, juvenil, pero constituyen un contrasentido para la parcela caduca. No son más que las alucinaciones de su agonía, palabras convertidas en frases, espíritus convertidos en fantasmas" (364). Este pasaje de la conclusión de El dieciocho brumario retoma la invocación inicial a las generaciones muertas, cuyas tradiciones pesan "como una pesadilla en el cerebro de los vivos" (288).

En el famoso comienzo de El dieciocho brumario, Marx especifica cuándo y cómo las generaciones muertas vuelven a la vida. Allí, escribe:

Los hombres hacen su propia historia, pero no la hacen a su libre arbitrio, en circunstancias elegidas por ellos mismos, sino en aquellas circunstancias que se encuentran directamente, que existen y les han sido legadas por el pasado. La tradición de todas las generaciones muertas oprime como una pesadilla el 
cerebro de los vivos. Y precisamente cuando éstos parecen disponerse a transformarse y a transformar las cosas, a crear algo nunca antes visto, en estas épocas de crisis revolucionaria, es precisamente cuando conjuran temerosos en su auxilio a los espíritus del pasado, toman prestados sus nombres, sus consignas de guerra, su ropaje, para representar, con este disfraz de vejez venerable y este lenguaje prestado, la nueva escena de la historia universal (288).

Los ejemplos franceses de Marx son la revolución burguesa que empezó en 1789 y que recurrió a Roma; la sublevación proletaria de 1848, que evocó la de 1789; y la revolución napoleónica de 1851, con su repetición del Primer Imperio. Si la historia se repite a sí misma, de alguna manera, sabemos que para Marx - y aquí retoma y a la vez transforma a Hegel - la repetición histórica toma la forma de diferencia genérica. Como explica, "Hegel afirma en alguna parte que todos los grandes hechos y personajes de la historia universal aparecen, diríamos, dos veces. Pero se olvidó agregar: una vez como tragedia y la otra como farsa" (288). Desde la caracterización de la historia como tragedia y farsa en la introducción - y esto ha sido señalado con frecuencia-, la representación de Napoleón que hace Marx se basa fuertemente en el lenguaje dramático y teatral. Marx utiliza el lenguaje teatral con el fin de sugerir el papel que tiene la representación dramática en el ámbito de la historia y la política. De hecho, en tanto que Napoleón III entendió este carácter teatral de la representación, argumenta Marx, se transformó en Napoleón III:

Viejo roué ladino, concibe la vida histórica de los pueblos y los grandes actos de gobierno y de Estado como una comedia, en el sentido más vulgar de la palabra, como una mascarada, en que los grandes disfraces, y las frases y gestos no son más que la careta para ocultar lo más mezquino y miserable [...]. El aventurero que tomase, lisa y llanamente, la comedia como tal comedia, estaba destinado a triunfar (327-328). 
Si Bonaparte tiene la perspicacia de analizar "la vida histórica de la nación" como una forma de teatro, sin embargo, parece olvidarse de tomar distancia del papel que él mismo desempeña: "Sólo después de eliminar a su solemne adversario, cuando él mismo toma en serio su papel imperial y cree representar, con su máscara napoleónica, al auténtico Napoleón, sólo entonces se convierte en víctima de su propia concepción del mundo, el payaso serio que ya no toma a la historia universal por una comedia, sino su comedia por historia universal" (328). Como señala Martin Harries en referencia a este pasaje,

Bonaparte queda sujeto a una ideología que antes ha reconocido como falsa y ha manipulado como el representante público de una "sociedad secreta" completamente diferente. Es cuando Bonaparte, vistiendo la máscara de Napoleón, "imagina que es el verdadero Napoleón", cuando se convierte en "la víctima de su propia concepción del mundo", repetición fársica más que autor original (Scare Quotes, 70).

Lo que aparece enfatizado en las dos instancias, no obstante, es el rol esencial de la representación en la política y la historia materiales, dentro del momento de la revolución, ya sea tragedia o farsa. Según Marx, la liberación de los trabajadores también va a depender de la representación literaria de un referente inexistente: "La revolución social del siglo XIX no puede sacar su poesía del pasado, sino solamente del porvenir" (El dieciocho brumario, 290). No el presente, el futuro: así como los revolucionarios burgueses ignoran lo que es por lo que fue, los revolucionarios socialistas deben ignorar lo que es por lo que será. Si bien la distancia entre las dos revoluciones es inmensa, ellas son similares en su puesta en acto de una realidad que es también ficción. Como los intereses de clase de los campesinos, la liberación de la clase del proletariado en El dieciocho brumario ha de constituirse, si está constituida en algún punto, por el acto que la representa. Al igual que en la carta con la que empecé este 
ensayo, el momento de transformación, el momento de cambio, viene con la literatura.

Si no puede haber revolución sin literatura, sin fábulas que se vuelvan acción, que hagan historia, al mismo tiempo, no puede haber literatura sin revolución - ninguna literatura que en principio no nos dé el poder de decirlo todo, de librarnos de las reglas, de desplazarlas y, de esa manera, de instituir y crear-. Como argumentaría Marx, es imposible no remitirse a un reino de libertad, uno más allá de la regulación colectiva de la necesidad, en el cual el trabajo excedente ya no sería un trabajo explotador, sino arte e invención. Desde el declarado interés de Sade en "decirlo todo" (Justine, 329), al "todo está permitido en el arte" de Trotsky (Blanchot, El libro por venir, 46), al "todo debe ser dicho. La libertad es la libertad de decir todo" de Blanchot ("La insurrección, la locura de escribir", 341), o el "¡Oh momento mágico, oh poesía de hoy: / contigo es posible decirlo todo!" (Taberna, 151) del poeta y guerrillero del Salvador Roque Dalton, hasta la afirmación de Derrida de que la literatura es una "institución ficticia que en principio le permite a uno decir todo" (Derrida, "This Strange Institution Called Literature", 36), la literatura nombra el acontecimiento de la libertad absoluta. Es por esto que, aunque fabulosa y precaria como el Estado que amenaza - también sin garantías-, la revolución a la que Blanchot se refiere nombra un momento de invención. No hay revolución sin literatura, entonces, también significa que no hay revolución sin invención - y lo que se inventa cada vez es la literatura, pero la literatura como la entiende Marx, es decir: la literatura como lo que aparece sólo en su desaparición, como lo que nunca es idéntico a sí mismo, como lo que, nunca saliéndose de la historia, participa en las relaciones políticas y cambios históricos, procesos de transformación, y lo hace mediante un lenguaje en cuyo movimiento se inscriben los trazos de lo histórico y lo político-. Como diría Blanchot, "la obra desaparece, pero el hecho de desaparecer se 
mantiene, aparece como lo esencial, como el movimiento que permite a la obra realizarse entrando en el curso de la historia, realizarse desapareciendo" ("La literatura y el derecho a la muerte", 21). Lo que se necesita es una forma de comunismo que posibilite que la literatura permanezca fiel a sí misma, pero a "sí misma" como aquella que nunca es simplemente "sí misma”. Es por esto que explica que

es comprensible la desconfianza que inspiran a los hombres comprometidos con un partido, a los que han tomado partido, los escritores que comparten su opinión; pues éstos también han tomado partido por la literatura, y la literatura, por su movimiento, niega a fin de cuentas la sustancia de lo que representa ("La literatura y el derecho a la muerte", 24).

Lo que está en juego para Blanchot no es simplemente la exigencia de una experiencia literaria de la revolución sino también una reconceptualización de la literatura y de la revolución. Como observa en las primeras oraciones de "La literatura y el derecho a la muerte", "la literatura empieza en el momento en que la literatura es pregunta" (9), es decir, cuando el lenguaje de un texto se transforma en literatura a través de una pregunta sobre el lenguaje en sí. Si la literatura apunta a transformar el lenguaje, no obstante, lo hace — como Blanchot y Marx nos dicen - para cambiar mucho más que el lenguaje, para transformar las relaciones en las cuales vivimos. Su lenguaje transformador no sólo permite acceder a la historia inscrita en ella, sino que también funciona para intervenir en las ya cambiantes relaciones históricas y políticas. "La literatura no es nada", escribe Blanchot.

Quienes la desprecian se equivocan al pensar que la condenan considerando que es nada. "Todo eso es sólo literatura". De ese modo se oponen a la acción, que es intervención concreta en el mundo, y a la palabra escrita, que sería manifestación pasiva 
en la superficie del mundo; los que están del lado de la acción repudian la literatura que no actúa mientras los que buscan la pasión se hacen escritores para no actuar. Pero eso equivale a condenarla y a amar por abuso. Si en el trabajo se ve el poder de la historia, la que transforma al hombre transformando el mundo, fuerza es reconocer en la actividad del escritor la forma por excelencia del trabajo (28-29).

Roque Dalton reitera este punto en uno de sus últimos poemas epigramáticos llamado "Arte poética", escrito poco antes de su asesinato en 1974. Dirigiéndose a la literatura misma, escribe: "Poesía / perdóname por haberte ayudado a comprender que no estás hecha sólo de palabras" (apud Alegría, "Roque Dalton: Poet and Revolutionary", XVII). La escritura posterior a las consecuencias de la stalinización, la revolución cubana, y la nueva izquierda internacional de los años sesenta, la estrategia de Dalton de usar el lenguaje, involucra un esfuerzo consistente de hacer referencia a la historia, pero a una historia que — como en Blanchot — viene en forma de escritura. Nos advierte que nos mantengamos lo más alerta posible a un lenguaje que realiza su trabajo histórico y político a través de la movilización de figuras, cuyos movimientos y múltiples significaciones aluden tanto al pasado lingüístico sellado en ellos como a la imprevisibilidad de un futuro que podría alterar, y por lo tanto crear, el sentido de nuestra existencia histórica. Que no pueda haber lenguaje que no se refiera a la historia, ni historia que no se refiera al lenguaje, significa que la tarea de leer históricamente (es decir, políticamente) requiere trazar no sólo el modo en el que el texto comparte su lenguaje con otro lenguaje (cómo está situado dentro de un contexto histórico particular o general, cómo está inscrito dentro de una cadena de textos), sino también lo que queda de idiomático en el texto (cómo confirma este contexto al mismo tiempo que lo traiciona, incluso lo traiciona con el fin de respetarlo). Esta es la tarea con la cual Roque Dalton nos pide que nos comprometamos cuando, 
revisando la afirmación de Marx de que la religión es el opio de los pueblos, responde, hablando de Macao y la trata de esclavos (aunque también quizás haya estado hablando de América Latina): "No siempre. // Porque, / por ejemplo, / en Macao, / el opio / es el opio del pueblo" (Taberna, 121). En toda su obra, Dalton nunca abandona las que son, para él, las "indeterminadas e indecisas" condiciones lingüísticas (y por lo tanto materialistas) de la acción política. Como señala en un poema titulado "Taberna”, escrito en Praga entre 1966 y 1967: “ADEMÁS ESTÁ EL PROBLEMA DE LA SINTAXIS, / UNO DEBE DARSE SU PUESTO” (165). Junto con Blanchot y Marx, Dalton nos pide que nos lancemos hacia el futuro, sin seguridad de determinación, sin conocimiento. La acción política debe su posibilidad a la experiencia de la indecisión — lo que aquí Dalton llama el problema de la sintaxis-, el hecho de que ésta siempre será su condición, puede confirmar la sospecha de Bataille de que "la literatura no puede asumir la tarea de ordenar la necesidad colectiva" (apud Nancy, "El comunismo literario", 123), pero al mismo tiempo, quizás ofrece la única posibilidad para una política que desea mantenerse abierta al futuro.

Una política como esta nos pediría que estuviéramos a la altura de lo que no puede medirse en el mundo, sin una ley establecida, sin proceso inevitable, sin predicción, sin cálculo - justicia absoluta, dignidad perfecta - y es por esto que es necesario inventar y crear el mundo otra vez, inmediatamente, aquí y ahora, a cada momento, sin referencia a un determinado ayer o mañana, lo que sería lo mismo que decir que es necesario, al unísono y al mismo tiempo, afirmar y denunciar el mundo tal cual es, para hacer del mundo un espacio a partir de sus propias contradicciones, lo cual nos impide llegar a saber por adelantado lo que se debe hacer, pero también nos impone la tarea de nunca hacer nada que no sea un mundo. ¿Qué significaría hacer un mundo? ¿Qué significaría inaugurar un mundo en el cual desplazamiento, racismo, nacionalismo, cla- 
ses ideológicas, sexismo y opresión económica de todo tipo ya no existieran? En qué va a transformarse nuestro mundo es algo que no podemos saber. Pero podemos actuar de tal manera que permita que este mundo sea un mundo capaz de abrirse a su propia incertidumbre. Debemos inventar un mundo, en vez de estar atados a uno, o soñando con otro. La invención nunca supone modelo o garantía, pero donde las certezas se deshacen, allí mismo se articula la fuerza con la que ninguna certidumbre puede medirse. Hagamos literatura porque, como sabemos, ni siquiera una sociedad comunista podría sobrevivir sin ella. Hagamos literatura entonces. Literatura con Marx. Literatura que haga su propio duelo, pero que, en su duelo, se acerque a sí misma como aquello que nunca es simplemente lo mismo, a lo que, en forma de sutil diferenciación, quizás algún día nos posibilite un futuro, pero un futuro que, en forma de literatura, prometa un mundo que no sea una simple repetición del pasado — un mundo que, porque siempre permanecerá abierto, todavía está por llegar.

\section{REFERENCIAS}

Alegría, Claribel, "Roque Dalton: Poet and Revolutionary", en Small Hours of the Night, trad. Jonathan Cohen et al., Hardie St. Martin (ed.), Willimantic, Curbstone Press, 1997, XV-XXIV.

Blanchot, Maurice, "La literatura y el derecho a la muerte", en De Kafka a Kafka, trad. Jorge Ferreiro, México, Fondo de Cultura Económica, 1991,37-41 ["Literature and the Right to Death", en P. Adams Sitney (ed.), The Gaze of Orpheus, and Other Literary Essays, trad. Lydia Davis, Nueva York, Station Hill P, 1981].

__, "La obra y el espacio de la muerte", en El espacio literario, trad. Vicky Palat y Jorge Jinkins, Paidós, Madrid/Buenos Aires, 1992, 77-98.

_ El El libro por venir, trad. Cristina de Peretti y Emilio Velasco, Madrid, Trotta, 2005. 
Blanchot, Maurice, "La insurrección, la locura de escribir", en $E l$ diálogo inconcluso, trad. Pierre de Place, Caracas, Monte Ávila, 1993, 349-367 ["Insurrection, the Madness of Writings", en The Infinite Conversation, trad. Susan Hanson, Minneapolis, U of Minnesota P, 1993].

__ " "Los tres lenguajes de Marx", en La amistad, trad. J. A. Doval Liz, Madrid, Trotta, 2007, 94-96 ["Marx's Three Voices", en Friendship, trad. Elizabeth Rottenberg, Standford, Standford UP, 1997].

_ , "There Could Be No Question of Ending Well", en The Book to Come, trad. Charlotte Mandell, Standford, Standford UP, 2002, 27-33.

Dalton, Roque, Taberna y otros lugares, La Habana, Casa de las Américas, 1969, 113-178 ["Tavern and Other Places", en Hardie St. Martin (ed.), Small Hours of the Night: Selected Poems of Roque Dalton, trad. Jonathan Cohen et al., Willimantic, CT, Curbstone P, 1996].

DERRIDA, Jacques, "This Strange Institution Called Literature: An Interview With Jacques Derrida", en Derek Attridge (ed.), Acts of Literature, New York, Routledge, 1992, 33-75.

Garces, María Antonia, Cervantes in Algiers: A Captive's Tale, Nashville, TN: Vanderbilt University, 2005.

HAMACHER, Werner, "Lingua Amissa", en Ghostly Damarcations: A Symposium on Jacques Derrida's, Michael Sprinker (ed.), New York, Verso, 1999, 192-193.

HARRIES, Martin, Scare Quotes From Shakespeare: Marx, Keynes, and the Language of Reenchantment, Standford, Standford UP, 2000.

JAMESON, Fredric, The Political Unconscious: Narrative as a Socially Symbolic Act, Nueva York, Routledge, 1983.

Kaufman, Robert, "Red Kant, or the Persistence of the Third 'Critique' in Adorno and Jameson", en Critical Inquiry, vol. 26, 4, verano 2000, 682-724.

LEZRA, JACQUES, Unspeakable Subjects: The Genealogy of the Event in Early Modern Europe, Stanford, Stanford UP, 1997.

Marcos, subcomandante, "The Punch Card and the Hourglass: Interview by García Márquez and Roberto Pombo", en New Left Review, 9, mayo-junio 2001, ver: <http://www.newleftreview. org/A2322>. 
MARX, Karl, "Carta al padre", en Karl Marx, Heinrich Marx, Cartas: Reflexiones entre padre e hijo, trad. Eduardo Martínez, Buenos Aires, Goncourt, 1985.

_- The Eighteenth Brumaire of Louis Bonaparte, Nueva York, International Publishers, 1998.

_- El dieciocho brumario de Luis Bonaparte, trad. O.P. Sanfot, Barcelona, Ariel, 1971.

Marx, Karl y F. Engels, La ideología alemana. Crítica de la novísima filosofía alemana en las personas de sus representantes. Feuerbach, B. Bauer y Stirner y del socialismo alemán en sus diferentes profetas, México, Grijalbo, 1987.

_- Cuestiones de arte y literatura, trad. Jesús López Pacheco, Barcelona, Península, 1975 [Marx and Engels on Literature and Art, Moscow, [s. e.], 1984].

NANCY, Jean-Luc, "El comunismo literario", La comunidad inoperante, trad. Manuel Garrido, LOM/Universidad ARCIS, Santiago, 2000, 123-136 [The Inoperative Community, trad. Peter T. Connor, Minneapolis, U of Minnesota P, 1991].

Petrey, Sandy, "The Reality of Representation: Between Marx and Balzac", en Philippe Desan, et al., Literature and Social Practice, Chicago, U of Chicago P, 1989, 69-89.

Prawer, S. S., Karl Marx and World Literature, Oxford, Oxford University Press, 1978.

SADE, Marquise de, Justine, Philosophy in the Bedroom, and Other Writings, trad. Richard Seaver and Austryn Wainhouse, Nueva York, Grove P, 1965. 